\title{
Long-term Group and Premature Drop out Groups in Psychotherapy: Yalom's 'Here and Now' Techniques
}

\author{
Boonyawee Senaboonyarit \\ School of Nursing Science, Assumption University, Thailand
}

Copyright $(2016$ by authors, all rights reserved. Authors agree that this article remains permanently open access under the terms of the Creative Commons Attribution License 4.0 international License.

\begin{abstract}
The Yalom's 'here-and-now' techniques-activation and illumination is worked particularly in each session of long-term group psychotherapy. Both activation and illumination help therapist interpret, reflect, and clarify individual's behaviors. In the premature, dropping out of group, the therapist also used both in order to do following benefits: reduce the clients' psychological distress, increase individual's self-esteem, and foster client's hope in group session as well as maintain positive outcome of long-term group psychotherapy. The volunteers in long-term group psychotherapy of the Thai Psychotherapist Association was observed and recorded the 'here-and-now' techniques by an observer when the premature drop out presented in the group process. The result of this study showed that most of Yalom's 'here-and-now' activation was demonstrated in premature drop out group.
\end{abstract}

Keyword Yalom 'Here-and-now', Long-term Group Psychotherapy, Premature Drop out

\section{Background/ Objectives and Goal}

In the long-term group psychotherapy, bonding and cohesion present in the group process. Bonding and cohesion influence positive emotions such as the sense of belonging, acceptance, care, and trust. ${ }^{(1-4)}$ However, the participants may also experience the premature termination of psychotherapy - group crisis. ${ }^{(5-8)}$ The group crisis leads to individual's emotional distresses such as disappointment, sad, anger, hopelessness, guilty and depression. ${ }^{(3,8-14)}$ Also, the result of premature drop-out group effected on the equilibrium of therapeutic process or/and leaving of some members from the group therapy. ${ }^{(1,3,15)}$ The therapy session can become an essential process to help individuals recover from emotional distress. The individuals who had experienced emotional crisis in the past, they need more emotional acceptance as well as establish bonding in group to increase one's self-esteem and hope. ${ }^{(2,8,4,16)}$ There are several techniques that the therapist can worked in group to help them such as empathy, catharsis, guidance, support, and reassurance. ${ }^{(1,17-19)}$ Hence, in the crisis of premature drop-out of group process not only requires the clinical experienced therapist who willing to work hard on one's feelings but also promotes positive relationships and prevents premature drop-out of the group members. ${ }^{(1,10,12,16,20-22)}$ The valuable experience in drop-out group, the stronger in persons and high level of self-esteem, whom are willing to become; if only the therapist utilizes the power of individuals properly toward premature drop-out situation. ${ }^{(1,3,16)}$ In group session, the more therapist offers multiple relationships for assisting the individual growth in 'here-and-now', the more accomplishment in group therapy will become. ${ }^{(23)}$ According to Yalom's theory, the group member acts as the power cell of the group. During therapeutic process, the therapist focuses on interaction and 'here-and-now' techniques to assist the member developing his/her interpersonal relationships. Within these techniques, the therapist focuses on almost of the present moment by allowing the participants to share their honest feelings and thoughts in order to obtain group's accomplishment.(Yalom \& Leszcz, 2005) In long-term group psychotherapy of Yalom's theory particularly demonstrates two techniques of 'here-and-now'-activation and illumination-within the group process. First, the activation of 'here-and-now' is the interaction process consists of personal feelings and thoughts. By using 'here-and-now' activation in group session, the therapist has to move the outside content inward to focus on the individual's present feelings, and simplify the abstract issue to more specific issue. In the group process, therapist will help the members to apply general information in order to their personal feelings or issues by shifting from personal feeling to interpersonal feeling or issue..$^{(3,23-26)}$ Second, the illumination of 'here-and-now' technique is the recognition of one's own behavior by understanding of one's behaviors may negatively affect others. Therapist will then advised 
the individual to practice more appropriate and positive behavior in order to avoid negative impacts to others. $^{(1,3,23-29)}$ Therefore, the premature drop-out group - group crisis presented in the current issue and immediate emotional crisis in group session, the group leader(i.e therapist) must apply the 'here-and-now' techniques concurrently within the group to help members identify level of psychological distress, facilitate resolution of interpersonal problem within the group, and maintain group's cohesiveness and bonding. For this reason, the main objective of this study is to examine with Yalom's 'here-and-now' techniques by observing the long-term group psychotherapy and therapist's action in 'here-and now' after the premature drop out. This research may influence new ideas for future psychotherapy research.

\section{Methods}

\subsection{Subject}

28 participants consisted of 17 women and 11 men $\left(M_{\text {age }}\right.$ $=30.3, S D=4.6$ ). Their age were between 20 to 30 year old. Their education levels are undergraduate 9 persons, Bachelor's degree are 13 persons, and Master degree 6 persons. Their career consisted of 17 clinical psychologists, 9 fourth year students, 1 teacher, and 1 physical therapy. Participants volunteered in the long term group psychotherapy, Thai Psychotherapist Association, from May 2013 to July 2015 . The long term group objective was to encourage members to accept their weakness and enhance members to be mature persons. After group orientation, subjects accepted informed consent for long term group psychotherapy. There were three groups. The long-term group psychotherapy sessions occurred once a week and each session is arranged approximately 90 minutes.

\subsection{Therapists and Observers}

The psychotherapy sessions are held by a licensed psychotherapist, who is both the trainer and chairperson of the Thai Psychotherapist Association This individual is specialized in psychotherapy training. He has been studying and practicing the Yalom's interpersonal theory in the group psychotherapy sessions for over 40 years. The observer of this study was a psychotherapist who is also the member of the Thai Psychotherapist Association with over 10 years of experience in the group psychotherapy training.

\subsection{Procedures}

The chairperson of the Thai Psychotherapist Association explained the objectives of the long-term group psychotherapy and asked participants for their consent to begin the experiment. If the individuals decided to volunteer in this experiment, they have to complete the demographic information. Then the group started working psychotherapy every week continuously; 90 minute/ one time per week. When the member drops out from the long-term group psychotherapies, the observer will now observe the in group process by using the tape-recorder to record the 'here-and-now' techniques. The situation and data record were analyzed based on Yalom's interpersonal theory. The content analysis was recorded word-by-word of each sentence to interpretation by using the patterns of Yalom's 'here-and-now'. The data were described as descriptive statistic.

\section{Results}

There were 28 subjects, which consisted of 17 women and 11 men from age 20 to 30 year old $\left(\mathrm{M}_{\text {age }}=30.3, \mathrm{SD}=\right.$ 4.6). Almost levels of education are usually students in undergraduate as well as those who graduated with Bachelor's degree. The psychotherapy sessions occurred once a week for two consecutive years, unless dropped out (i.e. premature drop-out group). Within two years, times of participation was averaged at 75.2 sessions $(S D=20.7)$. Three groups demonstrated of 'here-and-now' activation were used more than here-and-now-illumination as shown in Table 1. Total demonstration of here-and-now activation and its pattern were present in Table 2 . 
Table 1. The frequency of Yalom's 'here-and-now' in premature termination group. The descriptive data present--three groups demonstrated 'here-and-now' activation in the group process and compared with here-and-now illumination. The mean and standard deviation of both 'here-and-now' activation $\left(M_{\text {age }}=22.0, S D=3.0\right)$ and 'here-and-now' illumination $\left(M_{\text {age }}=3.0, S D=1.73\right)$ indicated that...?

The frequency of Yalom's here-and-now' in premature termination group

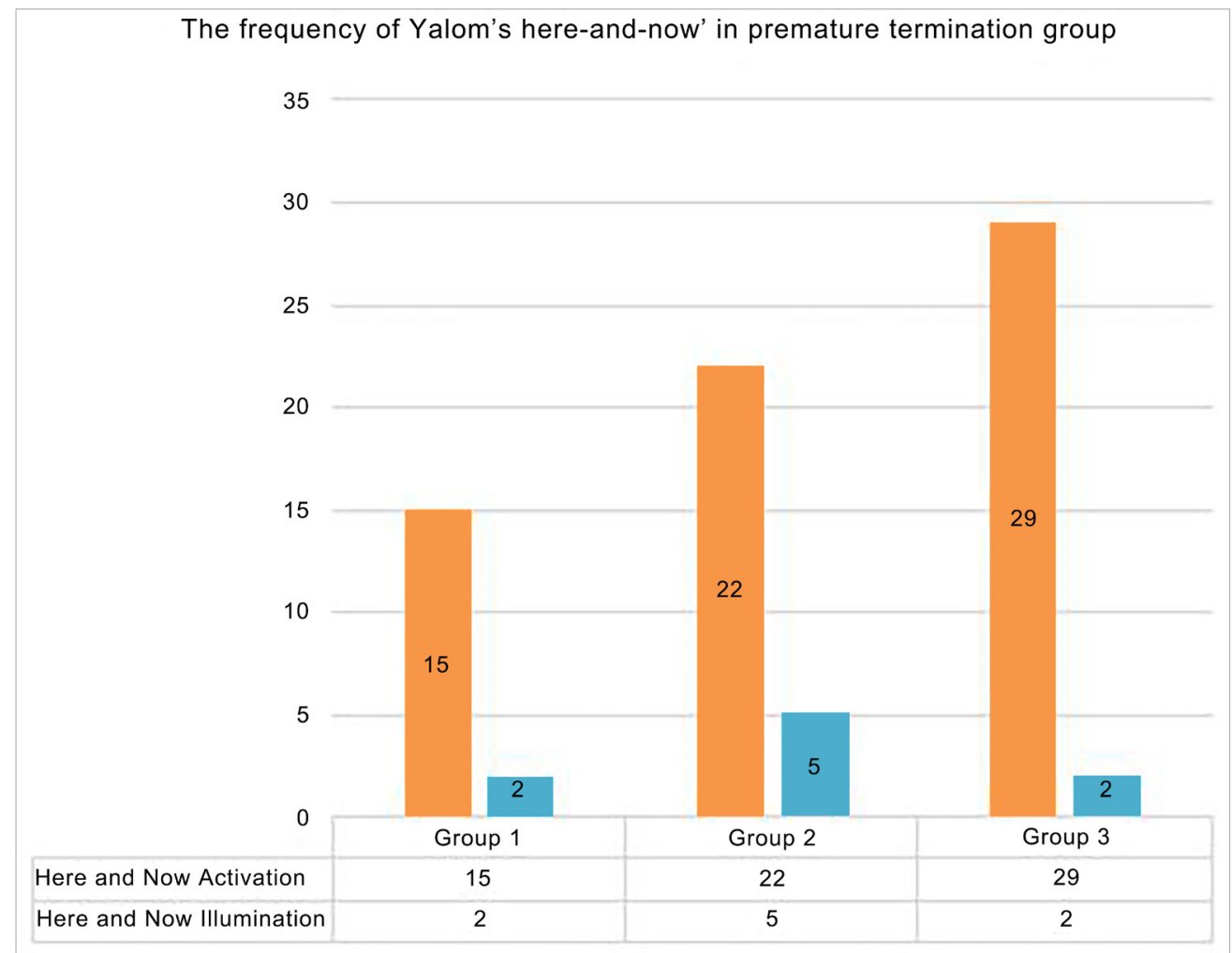

Table 2 The characteristic of 'here-and-now'activation. The four patterns of 'here-and-now' activation happened in premature drop out group. The individual feeling almost presented in the group process facilitating by clinical experienced psychotherapist.

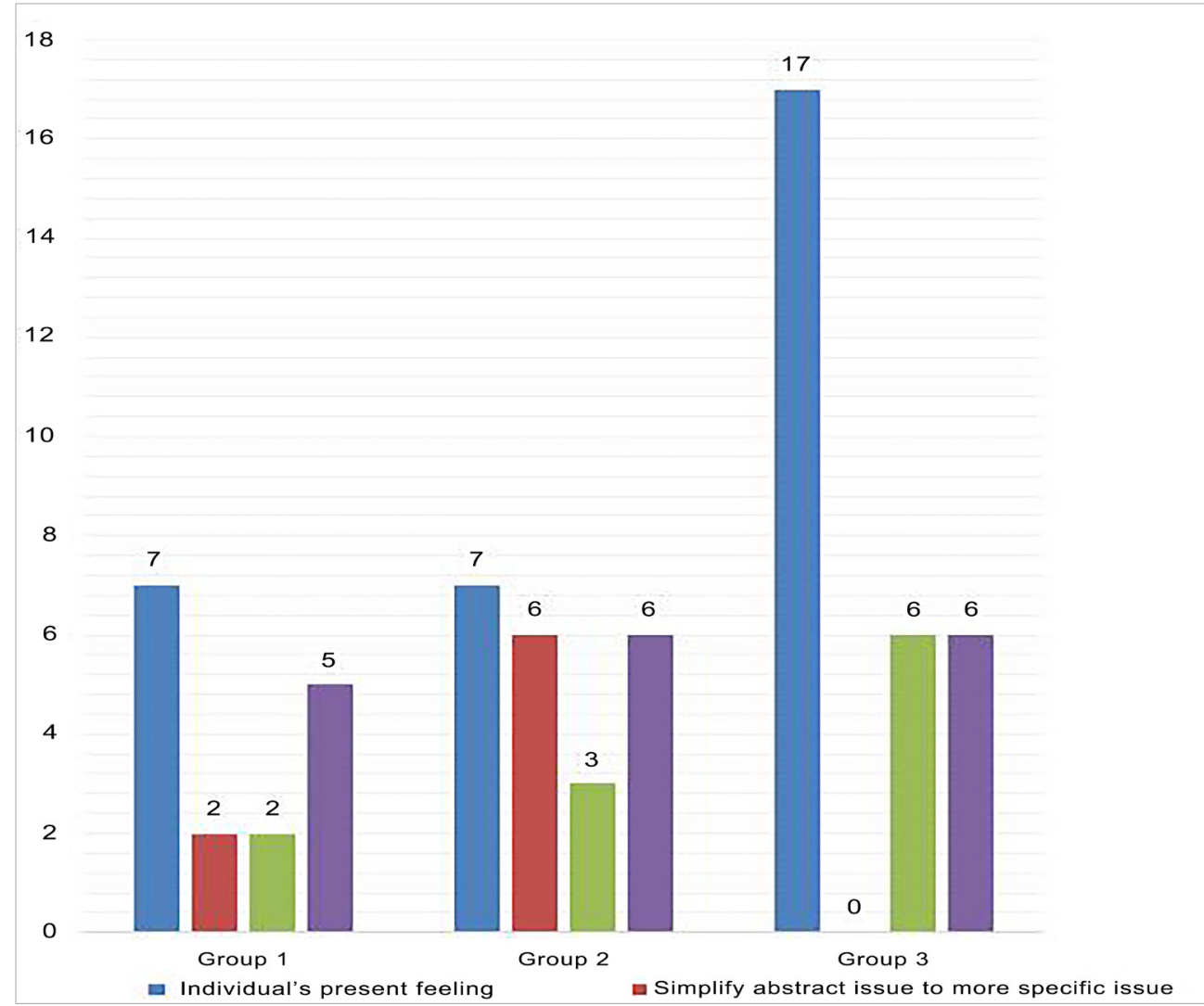




\section{1. 'Here-and-now' Activation Approach}

In the beginning of the group therapy session, the therapist asked the members to share his or her current feelings, thoughts, and opinions to the group members. There were four scenarios that therapist had analyzed. In the first scenario, the therapist examined the room and found that there were some members missing. Because of the differences in group members, it was important to keep track on how the other members feel about this situation. For example, the group member mentioned that "A member did not come today." "I thought the total number of group members were less than usual." "She did not come." The therapist said "Someone loosed from our group, how do you feel?" In the second scenario, a member approached the group and announced that she had to leave the study permanently due to a new job outside of the city. For example, the member said that "I got a new job offer and I must move to another city for my new job." "I needed to stop since this week beside, I would like to say goodbye to everybody". In the third scenario, the therapist used 'here-and-now' to facilitate the group members' feelings. For example, the therapist asked everyone in the group to share how did one feels about oneself. In the fourth scenario, the therapist was interested in the traumatized individual due traumatic experiences in the past. The therapist used 'here-and-now' to stimulate and engage with the quiet individual who did not say anything during session. For example, the therapist said "If I did not ask you, you might not talk to us." "It seemed like this situation stimulated you to be even more traumatized as same as your experience in the past."

\section{2. 'Here-and-now' Activation Approached to Individual's Thought}

About the individual's thought, the therapist used 'here-and-now' activation to approach one's thought. There were two situations. In situation one, the therapist said "I am interested in your idea. What are you thinking of?" In situation two, some group members were worried about the new members will cause them negative feelings of mistrust and unhappy. So, the therapist observed and asked group members directly, "What were you concerned about? Feel free to talk to me about all your needs." One of the members approach the therapist and shared one's feelings. The therapist asked, "Why didn't you want a new member to participate in our group? You kept quiet. How did you feel?" The therapist observed the member as he shared his feelings. Later, the therapist encouraged members to be more active by having the group members have conversation with each member. One of the topics was to discuss their thoughts and opinions on new members' admission and criteria. For instance, the therapist said "You are an adventurous person, what was your opinion about admission of new members?" Therapist stimulated another group member to share hisher idea. Therapist asked the group members, "In your perspective, what should you do, if our group needed a new member?" During the group session, the therapist observed the group members' interaction by start with one member and let him/her ask others' ideas or/and feelings. For example, "Do you know how the other feels? Do they have the same feelings and opinions with you?"

\section{3. 'Here-and-now' Activation Approached to Feeling and Thought of Reluctance Person}

There were four situations. In the situation one, a member described his/her thoughts and feeling of reluctance. So, the therapist encouraged the individual to be more engaged with one's self by interpretation. The member stated, "I hated working alone. Without help from others, I feel tired, however, I sometimes feel better to work alone." The member also stated, "I love to work with smart person in order to improve myself." The therapist motive the member, "It was your fantasy self-defense. In fact, you had to work with others whom you were appreciated by; however, sometimes you cannot find the right person to work with as how you have expected. In situation two, three members were absented from long-term group psychotherapy. These members can affect the "working-in" group process. The following session, the absentee approached the therapist and wanted to talk in the group session. The absentee explained, "I would like to talk about my absence. My absence impacted on both our group process and somebody that I didn't want. Last week, the group process did not work very well. I had more concerned about dropping out of group." In this situation, the therapist said, "You feel like this is because of the bonding you have to our group and you feel the responsibility to your group. It was the existential factor which you could not avoid." This situation, the therapist had to reduce her personal feelings by using 'here-and-now' and existential factor. In situation three, when the chairperson of group must leave the group psychotherapy because of maternity leave. A member who is a group member and close friend of chairperson said that "This moment was suitable time to talk to her in our group session." "Before leaving, she put efforts to helping us both transportation and caring for our general safety." The therapist said "This is the bonding of our long term group psychotherapy. In long term group and therapeutic process, everyone in the group is important to one another." In situation four, the group member talked about her reasons of leaving and she presented her ideas to the group member. "I cannot go back to my house by myself because of the danger lane at night." Therapist encourages the members by stating, "Because of the bonding between members in this group process, everyone influences one another even in difficult times during the sessions."

\subsection{Here-and-now Illumination}

After premature termination, the illumination of 'here-and-now' was displayed in the group session. The 
psychotherapist used 'here-and-now' illumination for immediate clarification and interpretation in order to improve individuals' personal growth. Several situations in the group session are presented as follows. In situation one, the therapist said "Someone had experienced grief and loss, he/she might understand very well." (The therapist turned face to a member in group.) "Since you were young, you had several losses." "If you improve your self-awareness and practice the social skills from this group, you will be able to help others effectively". "Because you believe that if you do the good deeds, the reward will return to you." In situation two, the therapist talked to the member about his/her job experience. The therapist said, "I remembered your story. You said that you feel sad and disappointed about a person. From my viewpoint, I thought you had a little experience of your job. If I were you, I would feel the same way like you did. However, I did not give up. For your new job, if you tried your best, you would learn more and gain more experiences."

\section{Discussion}

The premature drop out is the immediate situation--crisis and universal problem of every members in long-term group psychotherapy. ${ }^{(10)}$ These premature drop out impacted on the equilibrium of group process ${ }^{(1,3)}$. Some of group members have negative feelings of sadness, depression, anger, and guilty. For the group session, members must express these psychological problem especially immediate feelings and should accept support from the experienced clinical therapist. The therapist must display acceptance and genuineness to the members. ${ }^{(8,30)}$ From the content analysis, both of 'here-and-now' demonstrated in the group activation and illumination. The 'here-and-now' activation presented almost in all these groups drops out. For instance, each group had demonstrated one time of drop out. The member who caused the individual to not want to express his/her feels in the group. The member reduced their immediate traumatic pressure by changing his/her traumatic feeling to another issue. For example, member said "Thank you for your support". Therapist said, "You feel like your close friend would be far away ..." Another member said "We would like have a congratulation party for him." The therapist said, "You changed the issue because you were unbearable of any loss." This could be because of Thai culture--the man acts as the leader of family Thai men cannot express their feelings to others in the group very well. In severe case of loss in the past, the therapist needed to encourage other member and accept member's action because the member may not tolerate to his/her trauma again. ${ }^{(24)}$ When premature drop out group took placed, therapist needed to balance the equilibrium of the group by focusing on feelings and interactions. Although the group works till the working phase of psychotherapy, therapist had to demonstrate acceptance of drop out situation, emphatic understanding to group members' feeling and action. This premature drop out needed using 'here-and-now' activation to facilitate individual's feeling more than focusing on member's behavior. Almost all expression of members is centered on feeling with drop out person - sad, anxiety, and anger. Also, the members' attitude and idea to include new members was discussed in group. Therapist had to raise members' hope for example, "This trouble was the common in life, I did not stop working my long-term group" Another situation, therapist said "If he gone away, you had found the others in group to help" "The Samaritan is not only one person in this world." Therapist simplified all sentences that might cause the members in group confusion or misunderstood. For example, a member said that "This moment was suitable time to talk to her in group because she used to be the chairperson of our group." "Before leaving, she put effort to help us both transportation and our safety." "I was appreciated everybody's feeling." "I also had the same feeling as you." "Her maternity's absent had impacted on ours and even on my future." "To keep myself safety, I must travel during the day time, so I should move to another group of psychotherapy." The therapist said "These were the bonding of you to others in our long-term group psychotherapy." "In long-term group and therapeutic process, everybody in group was important however; sometimes you have no choices and should be prioritized of your own safety." The giving information also should be simple principle, knowledge, as well as general information..$^{(3,33)}$ to help member understanding common problem. The members in premature group drop out must handle this problem in group by giving support from member to member in order to adapt themselves. If the member do not balance of self-esteem, the anxiety will happen $^{\text {(34) }}$

\section{Conclusions}

The premature drop out is a crisis in long-term group psychotherapy. The interaction in group is important for members to share ideas and support together in order to relieve members' negative feelings or emotional distress. The 'here-and-now' activation will help group members to present their feelings and thoughts. In addition, the giving information and existential factors are used to help members' understand their feelings and help them to deal with depression anxiety and guilty in group. The therapist fostered installation of hope to the members in group process in order to encourage the client working in the long-term group psychotherapy continuously. The therapist should break down members' sentence structures to enhance understanding among group members.

\section{Limitation}

The representative sample of members of this study is the early adult group. 


\section{Acknowledgements}

The author had eligible to conduct this research in The Thai psychotherapist and feels grateful to Dr. Pramote Chaowasil who was sponsored to me until now.

\section{REFERENCES}

[1] American Group Psychotherapy Association (2007). Practice guidelines for group psychotherapy. New York: American Group Psychotherapy Association: pp.12-40.

[2] Burlinggame, G. M., Fuhriman, A., Johnson, J.E. (2001) Cohesion in group psychotherapy. New York: Oxford University Press: pp. 373-79.

[3] Yalom, I.D., Leszcz, M. (2005), The theory and practice of group psychotherapy. 5th ed. New York: Basic Books: pp.40-260.

[4] Alonso, J.T. (2011) Cohesion's relationship to outcome in group psychotherapy: a meta-analytic review of empirical research. (Theses and dissertations. institute of Psychology Paper 2658. Brigham Young University. (2011-07-04)

[5] Michael, W., Gene, P. (1993) A meta-analysis of psychotherapy dropout. Professional Psychology: Research and Practice, 24(2)190-95.

[6] Fiona, S.G., Margaret, L.G., Roger, D.W. (2008) Predictors of dropout from group therapy among patients with bipolar and substance use disorders. Drug Alcohol Depend, 94 (1-3): 272-75.

[7] J Scott, R., Walter, N.S., Joseph, J.S. (2007) Psychodynamic group psychotherapy: Therapeutic Factor in Group Psychotherapy. 4th ed. New York: Guilford: 207-11.

[8] Egan, J. (2005) Dropout and related factors in therapy. The Irish Psychologist, 32(2): 27-30

[9] Jensen, H. H., Mortensen, E. L., Lotz, M. (2014) Drop-out from a psychodynamic group psychotherapy outpatient unit: Nord J Psychiatry, 68 (8): 594-604.

[10] Wheeler, K. (2014) Psychotherapy for the advanced practice psychiatric nurse: how to guide for evidence based practice. USA: Spinger. pp. 649-710.

[11] Senaboonyarit, B. The Yalom's therapeutic factor using in long term group psychotherapy after premature drop out: The International Symposium on Social Sciences and Management (ISSM 2015): February 5, 2015 at Toshi Center Hotel, Tokyo, Japan.

[12] Roback, H.B. (2000) Adverse outcomes in group psychotherapy: risk factors, prevention, and research directions: J Psychother Pract Res, 9: (3):113-22.

[13] Sharf, J., Primavera, L.H, Diener, M. J. (2010) Dropout and Therapeutic alliance: A meta-analysis of adult individual psychotherapy. Psychotherapy: Theory, Research, Practice, and Training, 47(4):637-45.

[14] Swift, J. K, Whipple, J. L., Greenberg, R.P., Nominiak, N. (2012) Practice recommendations for reducing premature termination in therapy. Professional Psychology: Research \& Practice (PROF PSYCHOL RES PRACT), 43: 379-87.

[15] Barrett, M.S., Chua, W-J., Crits-christoph, P., Gibbons , M.B., Casiano, D., Thompson, D. (2008) Early withdrawal from mental treatment: implications for psychotherapy practice. Psychotherapy (Chic), 45(2): 247-67.

[16] Marmarosh, C., Holtz, A., Schottenbauer, M. (2005) Group cohesiveness, group-derived collective self-esteem, group-derived hope, and the well-being of group therapy members: Group dynamics: Theory, research, and practice, 9(1): 32-44.

[17] Garfield, S.L. (1998) The practice of brief psychotherapy. United States of America, John Wiley and Sons, 2ed.

[18] Wongpakaran T. (2009) Psychotherapy: Theory and Technique. Chiagmaisangsin, Chaingmai University. pp. 36-40.

[19] Ettin MF. (1992) Foundaion and application of group psychotherapy: a sphere of influence. United States, Allyn and Bacon. pp. 271-80

[20] Steinar L, Vegard B.J., Grete H. A., Knut A.H., Torleif R, Per H. (2012) Psychodynamic group psychotherapy: impact of group length and therapist professional characteristics on development of therapeutic alliance. CLIN PSYCHOL PSYCHOTHER, 19: (5)420-33.

[21] Tryon, G.S., Kane, A.S. (1990) The helping alliance and premature termination. Counselling Psychology Quarterly, 3(3): 233-389.

[22] Horvath A.O., Luborsky L. (1993) The role of the therapeutic alliance in psychotherapy. Journal of consulting and clinical psychology, 61(4): 561-573.

[23] Slavin, R.L. The significance of here-and-now disclosure in promoting cohesion in group psychotherapy: The 50 th Annual conference of American group psychotherapy association: Feb 20, 1992 New York.

[24] Yalom, I.D. (2001) The gift of therapy. United States, Harper Collins: pp. 48-114.

[25] Brems, C. (1999) Psychotherapy: Process and Technique. Viacom, Allyn and Bacon, pp. 207-333.

[26] Kivlighan, D.M. (2014). Three important clinical processes in individual and group interpersonal psychotherapy. Sessions. American Psychological Association, 51(1): 20-4.

[27] Lemma, A. (2003) Introduction to the practice of psychoanalytic psychotherapy. USA: John Wiley \& Sons, pp. 65-200.

[28] Krug, O.T., Bugental J., Yalom I.D., Two masters of existential therapy cultivate presence in the therapeutic encounter. 2009. Journal of humanistic psychology online SAGE

[29] Abramowitz, S. I. (1974) Comparative effectiveness of there-and-then versus here-and-now therapist interpretations in group psychotherapy: Journal of Counseling Psychology, 21(4): 288-93

[30] Kasper, L. B., Hill, C.E., Kivlighan, JR. D.M. (2008) Therapist immediacy in brief psychotherapy: case study I: Psychotherapy theory, Research, Practice, Training, 45(3): 
281-97.

[31] Stanley, B. (2002) A psychodynamic perspective on resistance in psychotherapy. Psychotherapy in practice, 58(2): 157-63.

[32] Chessick, R.D. (1998) Technique and practice of intensive psychotherapy. London: Jason Aronson.
[33] Sue, A.E. (2009) Therapeutic factors in group counseling: implications for audiologic rehabilitation: Perspectives on Aural Rehabilitation and Its Instrumentation; 16(1): 15-28.

[34] Stark, D.P.H., House, A. (2000) Anxiety in cancer patients: review. British Journal of Cancer, 83(10): 1261-67. 